\title{
Severe Acute Respiratory Syndrome Coronavirus-2 seroprevalence in South-Central Uganda, during 2019-2021
}

Charles Ssuuna 1*, Ronald Moses Galiwango ${ }^{1}$, Edward Nelson Kankaka', Joseph Kagaayi 1,2, Anthony Ndyanabo', Godfrey Kigozi ${ }^{1}$, Gertrude Nakigozi ${ }^{1}$, Tom Lutalo ${ }^{1,3}$, Robert Ssekubugu', John Bosco Wasswa', Anthony Mayinja', Martina Cathy Nakibuuka', Samiri Jamiru', John Baptist Oketch ${ }^{1}$, Edward Muwanga4, Larry William Chang ${ }^{1,5,6,7}$, Mary Kate Grabowski ${ }^{6}$, Maria Wawer ${ }^{1,6}$, Ronald Gray ${ }^{1,6}$, Mark Anderson ${ }^{8}$, Michael Stec ${ }^{8}$, Gavin Cloherty ${ }^{8}$, Oliver Laeyendecker ${ }^{7}$, Steven James Reynolds ${ }^{6,7,9}$, Thomas C. Quinn ${ }^{7,9}$ and David Serwadda ${ }^{1,2}$

\begin{abstract}
Background: Globally, key subpopulations such as healthcare workers (HCW) may have a higher risk of contracting SARS-CoV-2. In Uganda, limited access to Personal Protective Equipment and lack of clarity on the extent/pattern of community spread may exacerbate this situation. The country established infection prevention/control measures such as lockdowns and proper hand hygiene. However, due to resource limitations and fatigue, compliance is low, posing continued onward transmission risk. This study aimed to describe extent of SARS-CoV-2 seroprevalence in selected populations within the Rakai region of Uganda.
\end{abstract}

Methods: From 30th November 2020 to 8th January 2021, we collected venous blood from 753 HCW at twenty-six health facilities in South-Central Uganda and from 227 population-cohort participants who reported specific COVID19 like symptoms (fever, cough, loss of taste and appetite) in a prior phone-based survey conducted (between May and August 2020) during the first national lockdown. 636 plasma specimens collected from individuals considered high risk for SARS-CoV-2 infection, prior to the first confirmed COVID-19 case in Uganda were also retrieved. Specimens were tested for antibodies to SARS-CoV-2 using the CoronaChek ${ }^{\mathrm{TM}}$ rapid COVID-19 IgM/lgG lateral flow test assay. IgM only positive samples were confirmed using a chemiluminescent microparticle immunoassay (CMIA) (Architect AdviseDx SARS-CoV-2 IgM) which targets the spike protein. SARS-CoV-2 exposure was defined as either confirmed IgM, both IgM and IgG or sole lgG positivity. Overall seroprevalence in each participant group was estimated, adjusting for test performance.

Results: The seroprevalence of antibodies to SARS-CoV-2 in HCW was $26.7 \%$ [95\%Cl: 23.5, 29.8] with no difference by sex, age, or cadre. We observed no association between PPE use and seropositivity among exposed healthcare workers. Of the phone-based survey participants, 15.6\% [95\%Cl: 10.9, 20.3] had antibodies to SARS-CoV-2, with no difference by HIV status, sex, age, or occupation. Among 636 plasma specimens collected prior to the first confirmed COVID-19 case, $2.3 \%$ [95\%Cl: $1.2,3.5]$ were reactive.

\footnotetext{
*Correspondence: cssuuna@rhsp.org; ssuunacharles2015@gmail.com

${ }^{1}$ Rakai Health Sciences Program, P.O. Box 279, Kalisizo, Uganda

Full list of author information is available at the end of the article
} original author(s) and the source, provide a link to the Creative Commons licence, and indicate if changes were made. The images or other third party material in this article are included in the article's Creative Commons licence, unless indicated otherwise in a credit line to the material. If material is not included in the article's Creative Commons licence and your intended use is not permitted by statutory regulation or exceeds the permitted use, you will need to obtain permission directly from the copyright holder. To view a copy of this licence, visit http://creativecommons.org/licenses/by/4.0/. The Creative Commons Public Domain Dedication waiver (http://creativeco mmons.org/publicdomain/zero/1.0/) applies to the data made available in this article, unless otherwise stated in a credit line to the data. 
Conclusions: Findings suggest high seroprevalence of antibodies to SARS-CoV-2 among HCW and substantial exposure in persons presenting with specific COVID-19 like symptoms in the general population of South-Central Uganda. Based on current limitations in serological test confirmation, it remains unclear whether seroprevalence among plasma specimens collected prior to confirmation of the first COVID-19 case implies prior SARS-CoV-2 exposure in Uganda.

Keywords: SARS-CoV-2 seroprevalence, Healthcare workers, COVID-19, South-Central Uganda

\section{Background}

It is over a year since the Severe Acute Respiratory Syndrome Coronavirus 2 (SARS-CoV-2) emerged [1] as a global pandemic and as of the 2nd of August 2021, nearly two hundred million cases were reported globally with $>4,000,000$ fatalities [2]. Transmission occurs by respiratory droplets, aerosols, and via fomites and is higher in confined or congested spaces [3]. SARS-CoV-2 infection can be asymptomatic [4] with estimates ranging from 5 to $80 \%$ while symptoms are largely nonspecific and include features of flu-like illness [5]. Diagnosis of asymptomatic and mild cases may be missed due to prioritization of screening/confirmatory tests for individuals with moderate to severe symptoms. However, asymptomatic and pre-symptomatic persons can be highly contagious and contribute greatly to epidemic spread $[6,7]$.

As of the 3rd of August 2021, more than 94,000 cases with 2710 deaths were documented in Uganda [2]. Between October-December 2020, the second wave of community transmission was on the rise [8] dominated by the delta variant, despite earlier control measures that included a phased nationwide lockdown between March and August 2020 [9]. The SARS-CoV-2 diagnostic testing landscape in Uganda prioritizes testing for symptomatic persons. It is unknown how many infected asymptomatic persons are missed due to this symptom-based testing approach and how this impacts community transmission.

$\mathrm{HCW}$ in particular are at a higher risk of contracting SARS-CoV-2 $[10,11]$ and inadvertently transmitting it to their patients, some of whom may be immunocompromised. According to the World Health Organization (WHO), they account for $10 \%$ of the global SARS-CoV-2 burden [12]. This risk may be higher in countries like Uganda, due to shortage of Personal Protective Equipment (PPE) amidst unquantified community disease burden. Notably, several HCW in Uganda have been infected and a number have died [13].

Due to the limited testing capacity, there are likely to be many undetected community infections fueling the epidemic. It is also unknown if SARS-CoV-2 importation or exposure in Uganda might have occurred earlier than the first (official) case reported on the 21st of March 2020. We aimed at determining the prevalence of antibodies to SARS-CoV-2 among selected high-risk sub-populations in South-Central Uganda, including HCW, persons who previously reported specific Coronavirus disease 2019 (COVID-19) like symptoms (fever, cough, loss of taste and smell) in the preceding 30 days, between May and August 2020. Additionally, we aimed at exploring the possibility of prior SARS-CoV-2 importation/exposure in South-Central Uganda before confirmation of the first (official) case on the 21st of March 2020.

\section{Methods}

\section{Study design and setting}

This cross-sectional study was conducted at the Rakai Health Sciences Program (RHSP) with participants recruited from within and outside the Rakai Community Cohort Study (RCCS) in four districts of South-Central Uganda (Masaka, Kyotera, Rakai and Lyantonde). The RCCS is an open, population-based cohort in 40 communities in these districts with surveys conducted every 18 months among 23,000 adults, resident in fishing, agrarian, or peri-urban/trading community settings [14].

\section{Study population and sample size Healthcare workers (HCW)}

A total of $385 \mathrm{HCW}$ would yield an estimated prevalence of $\sim 50 \%$ with $5 \%$ precision and $80 \%$ power. Assuming a $60 \%$ response rate, $642 \mathrm{HCW}$ would be needed and a total of $753 \mathrm{HCW}$ participated. HCW were identified from twenty-six health facilities in the region between 30th of November 2020 and 8th of January 2021, prioritizing high volume facilities located near the UgandaTanzania border or along the Kampala-Mutukula highway serving mobile persons who may be at higher risk of SARS-CoV-2 acquisition. At the selected health facilities, all available, willing $\mathrm{HCW}$ were recruited into the study.

\section{Cohort participants}

115 participants would yield an estimated prevalence of $\sim 5 \%$ in the general population at the time with at least $4 \%$ precision (a detectable difference from zero) and $80 \%$ power. Assuming a $50 \%$ response rate, a total of 230 participants was required versus the 227 who participated-we prioritized cohort participants who previously reported COVID-19 like symptoms (fever, cough, loss of 
taste and/or loss of smell) in the preceding 30 days during an earlier phone-based survey conducted between May and August 2020. Blood samples from these participants were collected between 30th of November 2020 and 8th of January 2021.

\section{Pre-COVID-19 response samples (before first reported case in Uganda)}

595 participant samples would be required to estimate a prevalence of $\sim 1 \%$ with at least $0.8 \%$ precision (a detectable difference from zero) and $80 \%$ power. We retrieved 636 archived plasma specimens collected between October 2019 and March 18th, 2020 during the preceding survey round of the RCCS, before the first confirmed COVID-19 case in Uganda was reported. These samples are routinely collected and stored primarily for surveillance of HIV, as well as genetic studies of interest in future. We prioritized samples from "high-risk" participants (truck drivers, fisher folks, commercial sex work clients, traders/vendors, shopkeepers, bar owners/ workers, mechanics, and motorcycle riders)-particularly individuals living close to the Tanzanian border and along the Kampala-Mutukula highway due to their high mobility and interaction with cross-border populations.

\section{Sample/data collection Healthcare workers}

After consenting and before collection of $4 \mathrm{ml}$ of venous blood, a questionnaire was administered capturing data on demographics, occupation, previous known exposure to a COVID-19 patient, self-reported prior COVID-19 PCR testing results if any and use of Personal Protective Equipment among those with prior contact with a confirmed COVID-19 case. We did not collect data on specific testing dates for those that reported prior PCR tests.

\section{Cohort participants}

Following the first lockdown in Uganda on March 18th, 2020 , the routine in-person RCCS survey was temporarily modified to a phone-based survey, with added emphasis on knowledge about COVID-19, mobility, and symptoms. No blood samples were collected at the time. We re-contacted individuals, who had reported the symptoms of interest, to avail $4 \mathrm{ml}$ of venous blood collected in EDTA vacutainers for use in this evaluation (for those that consented). The whole blood was processed on the same day to yield plasma stored at $-80^{\circ} \mathrm{C}$ till testing.

\section{Pre-COVID-19 response samples}

The routine RCCS questionnaire had been administered and routine blood samples collected, which provided plasma specimens and metadata for the retrospective assessment. Plasma was frozen $\left(-80^{\circ} \mathrm{C}\right)$ until laboratory analysis.

\section{Laboratory analysis}

Frozen plasma was thawed and tested for antibodies to SARS-CoV-2 using the CoronaChek ${ }^{\mathrm{TM}}$ rapid COVID-19 IgM/IgG lateral flow test assay that uses the spike receptor binding domain (RBD) as the target antigen, following manufacturer's instructions. We did not encounter any invalid results that would require repeat testing (as indicated by the test kit manufacturer). This assay was previously validated with Ugandan samples, including 1077 pre-pandemic samples from the RCCS [15] with sensitivity at $81.1 \%$ (CI: 64.4-91.0) for IgM, 60.5\% (CI: 44.7-74.3) for IgG and 83.0 (CI: 68.9-91.5) for IgM/IgG combined while specificity was $100 \%$ (CI: 96.2-100.0) for IgM, IgG and IgM/IgG combined. Nevertheless, since low specificities of SARS-CoV-2 antibody assays have been reported, particularly from other malaria endemic regions $[16,17]$, any sample that was solely IgM positive by CoronaChek ${ }^{\mathrm{TM}}$ was retested by the Abbott ARCHITECT AdviseDx SARS-CoV-2 IgM chemiluminescent microparticle immunoassay (CMIA) (Abbott, Chicago, IL) to minimize false positivity. The reported positive predictive value of the AdviseDx SARS-CoV-2 IgM assay is $95 \%$ between 15 and 30 days post infection in confirmed cases, specificity is $99.56 \%$ among pre-COVID-19 samples, and within-lab precision of the assay is $<3 \%$ Coefficient of Variation.

\section{Data analysis}

SARS-CoV-2 exposure was defined as either IgM confirmed by the ARCHITECT CMIA assay, both IgM and IgG, or IgG sole positivity. Point prevalence and $95 \%$ confidence intervals were determined for each sub-group using the exact Clopper-Pearson method of calculating confidence intervals for binomial proportions. Overall seroprevalence in each participant group was adjusted for test performance [18]. Association with seroprevalence was evaluated using chi-square tests or fisher-exact tests with a $5 \%$ level of significance. Analyses were performed in $\mathrm{R}$ version 4.1.2.

\section{Results}

Healthcare workers' SARS-CoV-2 antibody test results

Most of the participants were female (64.54\%), median age was 32 years (IQR 18-71 years), and over one-third (38.1\%) were nurses. In the initial screening using the CoronaChek $^{\mathrm{TM}}$, 30.8\% (232/753) of HCW had detectable SARS-CoV-2 antibodies irrespective of isotype class. Of these, 119 tested positive for IgM only, 102 for both IgM and IgG, and 11 for IgG only. Of the initially $119 \operatorname{IgM}$ only reactive samples, 46 were confirmed positive when 
re-tested using the ARCHITECT assay. After accounting for test performance, the overall SARS-CoV-2 antibody seroprevalence among HCW was 26.7\% ( 201/753, 95\%CI: 23.5-29.8; Table 1). Majority (24/26) of the sampled health facilities had at least one healthcare worker who had antibodies to SARS-CoV-2. Seroprevalence at facilities ranged from 4.2 to $57.0 \%$ with a median of $20.0 \%$. Seroprevalence did not differ by HCW cadre, age, or sex (Table 2).

A total of $128 \mathrm{HCW}$ reported having undergone prior SARS-CoV-2 RT-PCR testing with 16 reporting a prior positive result. Of the 16 individuals, 8 still had detectable antibodies to SARS-CoV-2 (1 with IgM only, 1 with IgG only, 6 with both IgM and IgG). Out of $108 \mathrm{HCW}$ who reported a previous negative RT-PCR result, 29 (27\%) subsequently tested antibodies positive. Four individuals did not know their results.

\section{Exposure, use of Personal Protective Equipment (PPE),} and seroprevalence among $\mathrm{HCW}$

Twenty one percent $(156 / 753)$ of the HCW surveyed reported previous contact with a confirmed COVID-19 case. All 156 reported consistently using face masks during known exposure, with a few also using other forms of PPE such as face shields, gowns, aprons, and gloves
Table 2 Factors associated with SARS-CoV-2 seroprevalence among Healthcare workers

\begin{tabular}{|c|c|c|c|}
\hline $\begin{array}{l}\text { Sociodemographic } \\
\text { characteristics }\end{array}$ & $\begin{array}{l}\mathrm{n} \text { (row \%) } \\
\text { seropositive } \\
\text { Crude } \mathrm{N}=159\end{array}$ & $\begin{array}{l}\text { n (row \%) } \\
\text { seronegative } \\
\text { Crude } N=594\end{array}$ & $\mathrm{p}$-value \\
\hline \multicolumn{4}{|l|}{ Sex } \\
\hline Male & $61(22.8)$ & $206(77.2)$ & 0.442 \\
\hline Female & $98(20.2)$ & $388(79.8)$ & \\
\hline \multicolumn{4}{|l|}{ Age category } \\
\hline $18-24$ & $33(17.6)$ & $155(82.4)$ & 0.444 \\
\hline $25-34$ & $57(23.9)$ & $181(76.1)$ & \\
\hline $35-44$ & $39(20.2)$ & $154(79.8)$ & \\
\hline $45-54$ & $21(25.0)$ & $63(75.0)$ & \\
\hline $55+$ & $9(18.0)$ & $41(82.0)$ & \\
\hline \multicolumn{4}{|l|}{ Cadre } \\
\hline Medical Officer & $3(25.0)$ & $9(75.0)$ & 0.523 \\
\hline Clinical Officer & $8(30.8)$ & 18 (69.2) & \\
\hline Nurse (all levels) & $57(19.9)$ & $230(80.1)$ & \\
\hline $\begin{array}{l}\text { Lab tech (all } \\
\text { levels) }\end{array}$ & $16(26.2)$ & $45(73.8)$ & \\
\hline Other staff* & $75(20.5)$ & $290(79.5)$ & \\
\hline
\end{tabular}

*Cleaners, counselors, data clerks, drivers, cooks, security officers, and student nurses

Table 1 SARS-CoV-2 seroprevalence estimates, adjusting for test performance

\begin{tabular}{|c|c|c|c|c|}
\hline Category & $\begin{array}{l}\text { IgM_only (CoronaCheck, } \\
\text { then Architect) }\end{array}$ & $\begin{array}{l}\text { IgM_and_IgG } \\
\text { (CoronaCheck) }\end{array}$ & $\begin{array}{l}\text { IgG_only } \\
\text { (CoronaCheck) }\end{array}$ & Overall adjusted prevalence $(95 \% \mathrm{Cl})^{\mathrm{e}}$ \\
\hline \multicolumn{5}{|l|}{$\mathrm{HCW},(\mathrm{N}=753)$} \\
\hline Crude number $+v e^{a}$ & 46 & 102 & 11 & $200.8 / 753(26.7 \%, C l=23.5-29.8)$ \\
\hline Crude prevalence ${ }^{b}$ & $6.1 \%$ & $13.5 \%$ & $1.5 \%$ & \\
\hline Adjusted prevalence ${ }^{c}$ & $7.9 \%$ & $16.3 \%$ & $2.4 \%$ & \\
\hline Adjusted number $+v^{d}$ & 59.7 & 122.9 & 18.2 & \\
\hline \multicolumn{5}{|l|}{ Cohort participants, $(N=227)$} \\
\hline Crude number + ve & 7 & 15 & 5 & $35.4 / 227(15.6 \%, \mathrm{Cl}=10.9,20.3)$ \\
\hline Crude prevalence & $3.1 \%$ & $6.6 \%$ & $2.2 \%$ & \\
\hline Adjusted prevalence & $4.0 \%$ & $8.0 \%$ & $3.6 \%$ & \\
\hline Adjusted number + ve & 9.1 & 18.1 & 8.3 & \\
\hline \multicolumn{5}{|l|}{ Early samples, $(\mathrm{N}=636)$} \\
\hline Crude number + ve & 8 & 1 & 2 & $14.9 / 636(2.3 \%, \mathrm{Cl}=1.2,3.5)$ \\
\hline Crude prevalence & $1.3 \%$ & $0.2 \%$ & $0.3 \%$ & \\
\hline Adjusted prevalence & $1.6 \%$ & $0.2 \%$ & $0.5 \%$ & \\
\hline Adjusted number + ve & 10.4 & 1.2 & 3.3 & \\
\hline
\end{tabular}

${ }^{a}$ Crude number + ve are the number of participants who tested positive on that test

${ }^{\mathrm{b}}$ Crude prevalence $=$ crude number + ve/number of participants tested

${ }^{\mathrm{C}}$ Adjusted prevalence $=($ crude prevalence + specificity -1$) /($ sensitivity + specificity -1$)$. The sensitivity and specificity of CoronaCheck is $81.1 \%$ and $100 \%$ respectively for IgM; $60.5 \%$ and $100 \%$ respectively for IgG; and $83.0 \%$ and $100 \%$ for $\operatorname{lgM}$ and IgG combined. Sensitivity and specificity of the Architect assay is $95.0 \%$ and $99.56 \%$ respectively for IgM. Combined sensitivity of CoronaCheck and the Architect assay when used serially for lgM $=\operatorname{Se} 1 \times \operatorname{Se} 2=81.1 \% \times 95.0 \%=77.0 \%$; while the combined specificity of the two assays used serially $=1-(1-\mathrm{Sp} 1)^{*}(1-\mathrm{Sp} 2)=1-(1-100 \%) \times(1-99.56 \%)=100 \%$

${ }^{\mathrm{d}}$ Adjusted number $+\mathrm{ve}=$ adjusted prevalence $\times$ number of participants tested

${ }^{e}$ Overall adjusted prevalence $=($ Sum of adjusted numbers + ve on $\lg M$ only, $\lg M$ and $\lg G$, and $\lg G$ only $) /$ number of participants 
(Table 3). Despite reporting consistent use of face masks, $63 / 156$ (40\%, CI 33-49\%) of the known exposed HCW had antibodies to SARS-CoV-2.

Table 3 Association of Personal Protective Equipment use and seroprevalence among Healthcare workers who were contacts of confirmed COVID-19 cases

\begin{tabular}{|c|c|c|c|}
\hline & $\begin{array}{l}\mathrm{n}(\%) \text { Seropositive } \\
\text { Crude } \mathrm{N}=45\end{array}$ & $\begin{array}{l}\mathrm{n}(\%) \text { Seronegative } \\
\text { Crude } \mathrm{N}=111\end{array}$ & $p$-value \\
\hline \multicolumn{4}{|c|}{ Face masks, n (\%) } \\
\hline Yes & $45(29 \%)$ & $111(71 \%)$ & \\
\hline No & - & - & \\
\hline \multicolumn{4}{|c|}{ Gloves, n (\%) } \\
\hline Yes & $28(34 \%)$ & $55(66 \%)$ & 0.151 \\
\hline No & $17(23 \%)$ & $56(77 \%)$ & \\
\hline \multicolumn{4}{|c|}{ Face shields, n (\%) } \\
\hline Yes & $11(29 \%)$ & $27(71 \%)$ & 0.987 \\
\hline No & $34(29 \%)$ & $84(71 \%)$ & \\
\hline \multicolumn{4}{|c|}{ Gowns, n (\%) } \\
\hline Yes & $12(37.5 \%)$ & $20(62.5 \%)$ & 0.226 \\
\hline No & $33(27 \%)$ & $91(73 \%)$ & \\
\hline \multicolumn{4}{|c|}{ Aprons, n (\%) } \\
\hline Yes & $15(33 \%)$ & $31(67 \%)$ & 0.502 \\
\hline No & $30(27 \%)$ & $80(73 \%)$ & \\
\hline
\end{tabular}

\section{Cohort participants' SARS-CoV-2 antibody test results}

A total of 314 individuals in the prior phone-based survey had reported the symptoms of interest (cough, fever, loss of taste and loss of smell). We attempted to contact all these for participation in this current survey and recruited 227 (72\%). The others were not recruited due to either refusal or failure to locate them (unreachable telephone contacts and out-migration). Of those recruited, most $(69.1 \%)$ were female and median age was 39 years (IQR 20-49 years). Upon initial screening using the CoronaChek ${ }^{\mathrm{TM}}, 16.3 \%$ of the participants $(37 / 227)$ tested positive on IgM only, $2.2 \%(5 / 227)$ tested positive on IgG only whereas $6.6 \%$ $(15 / 227)$ were positive on both IgM and IgG. Following re-testing of the initially IgM only reactive samples using the ARCHITECT assay, 7/37 were confirmed positive. After accounting for test performance, the overall SARS-CoV-2 antibody seroprevalence among symptomatic cohort participants was $15.6 \%(\sim 35 / 227$, 95\% CI: 10.9, 20.3; Table 1). Seroprevalence did not differ by participant HIV status, sex, age, or occupation (Table 4).

Table 4 Factors associated with SARS-COV-2 seroprevalence among phone-based survey participants

\begin{tabular}{|c|c|c|c|}
\hline Sociodemographic characteristics & $\begin{array}{l}n \text { (row \%) seropositive Crude } \\
N=27\end{array}$ & $\begin{array}{l}n \text { (row \%) seronegative Crude } \\
\mathrm{N}=200\end{array}$ & p-value \\
\hline \multicolumn{4}{|l|}{ HIV status } \\
\hline Negative & $14(12.0)$ & $103(88.0)$ & \multirow[t]{2}{*}{1.000} \\
\hline Positive & $13(11.8)$ & $97(88.2)$ & \\
\hline \multicolumn{4}{|l|}{ Sex } \\
\hline Male & $9(12.9)$ & $61(87.1)$ & \multirow[t]{2}{*}{0.939} \\
\hline Female & $18(11.5)$ & $139(88.5)$ & \\
\hline \multicolumn{4}{|l|}{ Age category } \\
\hline $20-24$ & $0(0.0)$ & $10(100)$ & \multirow[t]{4}{*}{0.633} \\
\hline $25-34$ & $7(11.1)$ & $56(88.8)$ & \\
\hline $35-44$ & $14(11.9)$ & $104(88.1)$ & \\
\hline $45-54$ & $6(16.7)$ & $30(83.3)$ & \\
\hline \multicolumn{4}{|l|}{ Occupation } \\
\hline Agriculture for home use/barter & $10(17.9)$ & $46(82.1)$ & \multirow[t]{9}{*}{0.097} \\
\hline Agriculture for selling & $1(2.9)$ & $34(97.1)$ & \\
\hline Fishing & $3(20.0)$ & $12(80.0)$ & \\
\hline Shopkeeper & $3(25.0)$ & $9(75.0)$ & \\
\hline Trading/vending & $5(12.2)$ & $36(87.8)$ & \\
\hline Bar worker or owner & $2(33.3)$ & $4(66.7)$ & \\
\hline Waitress/Waiter/restaurant owner & $1(16.7)$ & $5(83.3)$ & \\
\hline Construction & $1(50.0)$ & $1(50.0)$ & \\
\hline Motorcycle riders (carrying passengers) & $1(25.0)$ & $3(75.0)$ & \\
\hline
\end{tabular}


SARS-CoV-2 antibody test results among plasma specimens collected prior to confirmation of the first COVID-19 case in Uganda

Upon initial screening using the CoronaChek ${ }^{\mathrm{TM}}, 7 \%$ $(47 / 636)$ of specimens had detectable antibodies to SARS-CoV-2 irrespective of isotype class. The majority (44) were positive on IgM only, 2 were positive on IgG only whereas 1 reacted for both IgM and IgG. Out of the 44 IgM sole positive samples, 8 were confirmed following re-testing using the ARCHITECT assay. After accounting for test performance, the overall SARS-CoV-2 antibody seroprevalence in these early samples was $2.3 \%(\sim 15 / 636$, $95 \%$ CI: $1.2,3.5$; Table 1 ). Of the 11 samples actually confirmed positive for IgM/IgG, 9 were collected between October and December 2019, and 2 collected between Jan-March 2020.

\section{Discussion}

These findings suggest a relatively high SARS-CoV-2 seroprevalence among $\mathrm{HCW}$ at almost all the selected health facilities (24/26) in South-Central Uganda and substantial seroprevalence in persons previously reporting specific COVID-19 like symptoms within the general population. There was also potentially a spike in transmission a few weeks prior to this evaluation with predominance of IgM only antibodies in most of the participants. This is similar to findings by Nguyen et al. showing higher COVID-19 incident reports by frontline health care workers largely arising from inadequacy of PPE among other factors[19] and emphasizes need to avail adequate PPE to healthcare workers following evidence[20] that adequate PPE (and other measures) can effectively protect healthcare workers against COVID-19. HCW should also be prioritized for vaccination whenever available. Limited PPE access may enhance epidemic spread given the large numbers of clients that healthcare workers handle.

There are challenges interpreting SARS-CoV-2 rapid serology in regions with high malaria endemicity as infection with Plasmodium species was shown to induce cross-reactive antibodies to carbohydrate epitopes on the SARS-CoV-2 spike protein $[17,21]$. It is thus unclear whether seroprevalence in plasma specimens collected prior to confirmation of the first COVID-19 case implies prior SARS-CoV-2 or other related coronavirus exposure or malaria in Uganda. One key limitation of this study is the limited (sub) populations that were evaluated which may affect generalizability at population level.

$\mathrm{HCW}$ are minimally protected by face masks and only a few had accesses to other PPE (face shields, gowns, aprons etc.) and this, coupled with likelihood of improper face mask use or lack of N95-level protection, could explain the positive COVD-19 antibody results observed even among participants reporting face mask use. Several undetected cases among $\mathrm{HCW}$ in this region is a potential driver of nosocomial spread. A moderate concordance between reported RT-PCR COVID-19 positives and antibody test outcome may reflect waning antibody levels as reported in several publications [22, 23].

\section{Conclusions}

Findings suggest a high seroprevalence of antibodies to SARS-CoV-2 among HCW and substantial exposure in persons presenting with specific COVID-19 like symptoms in the general population of South-Central Uganda. Based on current limitations in serological test confirmation, it remains unclear whether seroprevalence in plasma specimens collected prior to confirmation of the first COVID-19 case implies prior SARS-CoV-2 exposure in Uganda.

\section{Abbreviations \\ SARS-CoV-2: Severe Acute Respiratory Syndrome Coronavirus 2; HCW: Healthcare workers; COVID-19: Coronavirus disease 2019; CMIA: Chemilumi- nescent microparticle immunoassay; WHO: World Health Organization; PPE: Personal Protective Equipment; UNCST: Uganda National Council for Science and Technology; RCCS: Rakai Community Cohort Study; RHSP: Rakai Health Sciences Program.}

\section{Acknowledgements}

Samples/Data collection: RCCS field team, District Health Officers of Rakai, Kyotera, Lyantonde and Masaka districts, Prossy Namutebi, Wilson Bwanike; Data management: Damalie Nansimbi, Muhammed Mugerwa, Darix Ssebagala Kigozi.

\section{Authors' contributions}

Protocol development: RMG, DS, ENK, CS, TCQ, KMG, LWC, SJR, MJW, RHG; Study implementation: CS, RMG, DS, RS, JBW, AN, EM, MCN, SJ, JBO, AM, MA, MS, GC; Manuscript development: CS, DS, RMG, ENK, JK, GK, GN, TCQ, KMG, LWC, SJR, TL, MJW, RHG, OL. All authors read and approved the final manuscript.

\section{Funding}

This work was funded by the Government of Uganda through Makerere University Research and Innovations Fund (Grant number RIF/COVID/075, https://rif.mak.ac.ug/) and in part by the Division of Intramural Research, National Institute of Allergy, and Infectious Diseases ( $\mathrm{NIH}$, https://www.niaid. nih.gov/about/dir) and the United States National Institutes of Health Fogarty International Center (D43TW010557). The funders had no role in study design, data collection and interpretation, or the decision to submit the work for publication.

\section{Availability of data and materials}

All data generated or analyzed during this study are included in this published article.

\section{Declarations}

Ethics approval and consent to participate

All methods of this study were carried out in accordance with the Uganda National Council for Science and Technology (UNCST) guidelines, the body that regulates research in Uganda. It was approved by the Uganda Virus Research Institute's Research Ethics Committee (Ref. GC/127/20/08/785), registered, and cleared by the UNCST (registration number HS878ES). Written informed consent was obtained from participants before blood specimens and other data were collected. Also, only archived plasma specimens 
(collected prior to confirmation of the first COVID-19 case) from Rakai Community Cohort Study (RCCS) participants that had provided prior written informed consent for use of their blood specimens in future studies were retrieved to assess prior SARS-CoV-2 exposure in Uganda. All participants were aged 18 years and above. No informed consent from 'Legally authorized representatives/parents' of minors below 16 years of age was thus required.

\section{Consent for publication}

Not applicable.

\section{Competing interests}

The authors declare that they have no competing interests.

\section{Author details}

${ }^{1}$ Rakai Health Sciences Program, P.O. Box 279, Kalisizo, Uganda. ${ }^{2}$ Makerere University School of Public Health, Kampala, Uganda. ${ }^{3}$ Uganda Virus Research Institute, Entebbe, Uganda. ${ }^{4}$ Kyotera District Health Office, Kyotera District Local Government, Ministry of Health, Kyotera, Uganda. ${ }^{5}$ Department of International Health, Johns Hopkins Bloomberg School of Public Health, Baltimore, MD, USA. ${ }^{6}$ Department of Epidemiology, Johns Hopkins Bloomberg School of Public Health, Baltimore, MD, USA. ${ }^{7}$ Division of Infectious Disease, Division of Medicine, Johns Hopkins School of Medicine, Baltimore, MD, USA. ${ }^{8}$ Abbott Laboratories, Abbott Diagnostics Division, Abbott Park, LL, USA. ${ }^{9}$ Division of Intramural Research, National Institute of Allergy and Infectious Diseases, National Institutes of Health, Bethesda, MD, USA.

Received: 8 October 2021 Accepted: 11 February 2022

Published online: 21 February 2022

\section{References}

1. Lescure F-X, Bouadma L, Nguyen D, Parisey M, Wicky P-H, Behillil S, et al. Clinical and virological data of the first cases of COVID-19 in Europe: a case series, Lancet Infect Dis, 2020:20:697.

2. Johns Hopkins University, cartographer JHU Corona Virus Resource Center. Baltimore, MD 21218, United States2020.

3. Meyerowitz EA, Richterman A, Gandhi RT, Sax PE. Transmission of SARSCoV-2: a review of viral, host, and environmental factors. Ann Internal Med. 2020;174:1037.

4. Yanes-Lane M, Winters N, Fregonese F, Bastos M, Perlman-Arrow S, Campbell JR, et al. Proportion of asymptomatic infection among COVID19 positive persons and their transmission potential: a systematic review and meta-analysis. PLoS ONE. 2020;15(11):e0241536.

5. Arons MM, Hatfield KM, Reddy SC, Kimball A, James A, Jacobs JR, et al. Presymptomatic SARS-CoV-2 infections and transmission in a skilled nursing facility. New Engl J Med. 2020;382:2081.

6. Nikolai LA, Meyer CG, Kremsner PG, Velavan TP. Asymptomatic SARS Coronavirus 2 infection: invisible yet invincible. Int J Infect Dis. 2020;100:112.

7. Furukawa NW, Brooks JT, Sobel J. Evidence supporting transmission of severe acute respiratory syndrome coronavirus 2 while presymptomatic or asymptomatic. Emerg Infect Dis. 2020;26(7).

8. Oketch B, Ebong P, Muhereza R, Ssenkabirwa A, Jjingo MF, Kalokwera P, et al. Health facilities run out of space as Covid-19 cases rise. Daily Monitor. 2020

9. Ahimbisibwe P. Museveni orders two-week lockdown as COVID-19 cases rise. Daily Monitor. 2020.

10. Ran L, Chen X, Wang Y, Wu W, Zhang L, Tan X. Risk factors of healthcare workers with corona virus disease 2019: a retrospective cohort study in a designated hospital of Wuhan in China. Clin Infect Dis. 2020;71:2218.

11. Wang $X$, Jiang $X$, Huang $Q$, Wang H, Gurarie D, Ndeffo-Mbah M, et al. Risk factors of SARS-CoV-2 infection in healthcare workers: a retrospective study of a nosocomial outbreak. Sleep Med X. 2020;2:100028.

12. Papoutsi E, Giannakoulis VG, Ntella V, Pappa S, Katsaounou P. Global burden of COVID-19 pandemic on healthcare workers. Eur Respir Soc. 2020

13. Twinamukye P. Uganda loses 58 doctors, nurses within one year. Daily Monitor 2021

14. Chang LW, Mbabali I, Kong X, Hutton H, Amico KR, Kennedy CE, et al. Impact of a community health worker HIV treatment and prevention intervention in an HIV hotspot fishing community in Rakai, Uganda
(mLAKE): study protocol for a randomized controlled trial. Trials. 2017;18(1):1-12.

15. Baker OR, Grabowski MK, Galiwango RM, Nalumansi A, Serwanga J, Clarke W, et al. Differential performance of CoronaCHEK SARS-CoV-2 lateral flow antibody assay by geographic origin of samples. J Clin Microbiol. 2021:JCM. 00837-21.

16. Woodford J, Sagara I, Kwan J, Zeguime A, Zaidi I, Attaher O, et al. SARSCoV-2 seroassay optimization and performance in a population with high background reactivity in Mali. 2021.

17. Lapidus S, Liu F, Casanovas-Massana A, Dai Y, Huck JD, Lucas C, et al. Plasmodium infection induces cross-reactive antibodies to carbohydrate epitopes on the SARS-CoV-2 Spike protein. medRxiv. 2021;107:77.

18. Sempos $C T$, Tian L. Adjusting coronavirus prevalence estimates for laboratory test kit error. Am J Epidemiol. 2021;190(1):109-15.

19. Nguyen LH, Drew DA, Graham MS, Joshi AD, Guo C-G, Ma W, et al. Risk of COVID-19 among front-line health-care workers and the general community: a prospective cohort study. The Lancet Public Health. 2020;5(9):e475-83.

20. Yassi A, Grant JM, Lockhart K, Barker S, Sprague S, Okpani Al, et al. Infection control, occupational and public health measures including mRNAbased vaccination against SARS-CoV-2 infections to protect healthcare workers from variants of concern: a 14-month observational study using surveillance data. medRxiv. 2021;9:226.

21. Grifoni A, Weiskopf D, Ramirez SI, Mateus J, Dan JM, Moderbacher $\mathrm{CR}$, et al. Targets of T cell responses to SARS-CoV-2 coronavirus in humans with COVID-19 disease and unexposed individuals. Cell. 2020:181(7):1489-501.

22. Choe PG, Kang CK, Suh HJ, Jung J, Song K-H, Bang JH, et al. Waning antibody responses in asymptomatic and symptomatic SARS-CoV-2 infection. Emerg Infect Dis. 2020;27:327.

23. Perreault J, Tremblay T, Fournier M-J, Drouin M, Beaudoin-Bussières $G$, Prévost J, et al. Waning of SARS-CoV-2 RBD antibodies in longitudinal convalescent plasma samples within 4 months after symptom onset. Blood. 2020;136(22):2588-91.

\section{Publisher's Note}

Springer Nature remains neutral with regard to jurisdictional claims in published maps and institutional affiliations.

Ready to submit your research? Choose BMC and benefit from

- fast, convenient online submission

- thorough peer review by experienced researchers in your field

- rapid publication on acceptance

- support for research data, including large and complex data types

- gold Open Access which fosters wider collaboration and increased citations

- maximum visibility for your research: over $100 \mathrm{M}$ website views per year

At BMC, research is always in progress.

Learn more biomedcentral.com/submissions 